\title{
Dietary macro- and micro-nutrient intake among a cohort of pre-school children from southern Sri Lanka
}

\author{
M Hettiarachchi $^{1}$, C Liyanage ${ }^{2}$ \\ (Index words: preschool children, dietary intake, energy intake, micro-nutrient intake)
}

\begin{abstract}
Objective To establish a database on dietary intake among children aged 3-5 years in southern Sri Lanka.

Methods A retrospective, quantitative method (24-hour dietary recall on 3 consecutive days) in combination with a food composition database was used to assess the nutrient intake among 248 children in Galle. Anthropometry measurements were done to assess their nutritional status.

Results There were no significant correlations between the constituents of the diet with the anthropometric parameters. The overall mean (SD) energy intake of male children 6.23 (1.3) MJ/day was significantly higher $(p=0.05)$ than female counterparts [5.75 (1.3) MJ/day]. $44.0 \%(n=45)$ of males and $55.0 \%(n=57)$ of females had an energy intake below the recommended level. None of the females of 3 years of age met the daily energy requirement.

Conclusions The intake of energy, protein, calcium, $\beta$-carotene, vitamin $D$ and iron was satisfactory in preschool children. Consumption of nutrients except iron and energy was better in males than in females. The dietary macro- and micro- nutrient intake by both sexes exponentially increased with age.
\end{abstract}

\section{Introduction}

Nutritional status of preschool children should be a national priority because they can become victims of malnutrition and infection easily. Nutrients affect their physical growth and development, maintenance of normal body functions and physical activities [1]. The rate of growth and development depends to a large extent on the adequacy of diet consumed by them.

The planning and implementation of effective nutritional intervention programmes should be based on the specific needs of individuals or communities [2]. Food intake data of children below 5 years of age available at present are semi-quantitative and obtained through food frequency level (weekly food consumption without obtaining portion sizes). Therefore, the present paper is the first attempt to appraise food consumption patterns and nutrient intake of a cohort of preschool children in southern Sri Lanka. We used a retrospective, quantitative method (3 day 24-hour dietary recall) in combination with a food composition database to assess the nutrient intake in a selected sample of children aged 3-5 years.

\section{Methods}

The study was conducted in year 2007 in the University field training area (Bope-Poddala health division) after obtaining approval from the Ethical Review Committee of the Faculty of Medicine, Galle. Two wellbaby-clinics that were conducted by 8 public health midwives (PHM) were purposively selected out of 4 clinics in this division. Two PHM areas from each of the 2 clinics were selected by simple random sampling. Parents of randomly selected children aged 3-5 years in these PHM areas $(n=267)$ were invited to a meeting at which the purpose of the study (procedure involved in obtaining dietary intake data) were explained in detail. They were demonstrated how to measure the portion size using household measuring units. They were given an opportunity to ask questions regarding the study. Informed written consent was obtained from parents of each study participant.

Children who had a history of medical conditions lasting more than one month $(\mathrm{n}=7)$ and consumed medications, including vitamin or mineral preparations for more than one month $(\mathrm{n}=12)$, were not included in the study. Height, weight and medical history were obtained, and a brief physical examination was conducted. Height and weight were measured using a portable stadiometer and a beam balance respectively. Dietary intake was assessed by the 24-hour recall method on 3 consecutive days from the mother (in some children the father participated, however same individual was present on all 3 days). Intake of all foods, drinks and snacks during the previous day were recorded. Data collectors were trained to record the food intake on a standard format. Special attention was given to estimation of portion sizes using household measuring units. After completion, the food quantities were converted to nutrient intake by each participant using food

${ }^{1}$ Nuclear Medicine Unit, ${ }^{2}$ Department of Community Medicine, Faculty of Medicine, University of Ruhuna, Sri Lanka.

Correspondence: MH, e-mail <nmu_galle@yahoo.com>. Received 11 December 2009 and accepted 5 April 2010. Competing interests: none declared. 
composition tables [3] and this was further compared with recommended dietary allowances (RDA) established by the Ministry of Health [4] to assess the adequacy of their diet.

The NutStat programme of the Epi-info version 3.4.1 (2008) for Windows was used to generate Z-scores of weight-for-age (WAZ), height-for-age (HAZ) and weightfor-age (WHZ). A Z-score $<-2.0$ from the reference median was used to detect wasting, stunting and thinness respectively. The average energy and nutrient intake have been presented as a mean of the 3-day intake. Data were analysed using SPSS version 10.0 (Chicago, USA). Student t-test was used to compare males and females. $P$ values less than 0.05 were considered to be significant.

\section{Results}

A total of 248 children (122 males and 126 females) participated. There was no difference in the age distribution $(p=0.17)$ by sex. Mean age of males was 51.0 (SD, 7.2) months and 48.7 (7.5) months in females. Male children had mean weight of $14.0(2.2) \mathrm{kg}$ and a mean height of $100.7(5.9) \mathrm{cm}$. In female children those were $13.3(2.0) \mathrm{kg}$ and $99.2(5.9) \mathrm{cm}$ respectively (Table 1). The body mass index also showed a significant difference $(p=0.03)$; mean levels of $13.7(1.1) \mathrm{kg} / \mathrm{m}^{2}$ in males and $13.5(0.9) \mathrm{kg} / \mathrm{m}^{2}$ in females.
None of the children below 3 years of age was stunted (HAZ <-2.0) (Table 2). Overall stunting was 3\% (3 each from males and females) with underweight (WAZ $<-2.0$ ) in $25 \%(n=25)$ of males and $26 \%(n=27)$ of females. The prevalence of thinness as an indicator of malnourishment (WHZ $<-2.0)$ was seen among $23 \%(n=23)$ of males and $16 \%(n=17)$ of females (Table 2$)$.

Data on daily mean dietary nutrient intake by both sexes in each age category are presented in Tables 3-5. The survey data sheets that lacked information on any of the 3 days were excluded $(n=28)$. Further, incomplete recall or unrealistic data, that could not be corrected reliably, were also rejected $(n=14)$. Hence, data have been reported on 206 participants. Overall mean dietary intake of energy among males (6.23 (1.3) MJ/day) was significantly higher $(p=0.05)$ than females $(5.75(1.3) \mathrm{MJ} /$ day $)$. The contribution from dietary fat towards the daily energy requirement was $16 \%$ among males and $15 \%$ among females respectively. Although, there were statistically significant differences in mean daily intake of some of the nutrients between males and females by age groups (Table 3 and 5) it was not evident in the total sample. The percentage of participants with energy intake below RDA were $44 \%$ among males and $55 \%$ among females. None of the 3 -year old females met the daily energy requirement.

Table 1. Anthropometric indices of the study sample ${ }^{1}$

\begin{tabular}{|c|c|c|c|c|c|}
\hline Age & Sex & $n$ & Weight (kg) & Height (cm) & $B M I\left(\mathrm{~kg} / \mathrm{m}^{2}\right)$ \\
\hline \multirow[t]{2}{*}{$<36.0$ months } & Male & 19 & $12.13(1.8)$ & $92.94(4.0)$ & $13.98(1.3)$ \\
\hline & Female & 18 & $11.38(1.2)$ & $91.04(3.9)$ & $13.71(0.7)$ \\
\hline \multirow[t]{2}{*}{$36.1-48.0$ months $^{2}$} & Male & 43 & $13.37(1.4)$ & $98.78(3.4)$ & $13.67(1.0)$ \\
\hline & Female & 53 & $12.66(1.4)$ & $97.71(3.8)$ & $13.23(1.0)$ \\
\hline \multirow[t]{2}{*}{$48.1-60.0$ months } & Male & 60 & $15.10(2.2)$ & $104.61(4.6)$ & $13.75(1.3)$ \\
\hline & Female & 53 & $14.69(1.8)$ & $103.82(4.2)$ & $13.60(1.2)$ \\
\hline \multirow[t]{2}{*}{$\mathrm{All}^{3}$} & Male & 122 & $14.02(2.2)$ & $100.74(5.9)$ & $13.78(1.2)$ \\
\hline & Female & 126 & $13.31(2.0)$ & $99.25(5.9)$ & $13.45(1.0)$ \\
\hline
\end{tabular}

\footnotetext{
${ }^{1}$ Results presented as mean (SD), there were 248 children in the study sample and abbreviations used BMI - body mass index.

${ }^{2}$ Males had higher weight $(p=0.02)$ and $\mathrm{BMI}(\mathrm{p}=0.03)$ in this age group.

${ }^{3}$ Males had higher weight $(p=0.008)$, height $(p=0.05)$ and BMI $(p=0.03)$ over the females.
} 
Table 2. Nutritional status of the study sample ${ }^{1}$

\begin{tabular}{|c|c|c|c|c|c|c|c|c|}
\hline Age & Sex & $n$ & WAZ & $H A Z$ & WHZ & Stunted & Underweight & Thinness \\
\hline \multicolumn{9}{|c|}{$<36.0$ months } \\
\hline & Male & 19 & $-1.26(1.2)$ & $-0.50(0.2)$ & $-1.53(1.0)$ & - & $32 \%(6)$ & $32 \%(6)$ \\
\hline & Female & 18 & $-1.62(0.8)$ & $-0.51(0.7)$ & $-1.57(0.6)$ & - & $33 \%(6)$ & $17 \%(3)$ \\
\hline \multicolumn{9}{|c|}{ 36.1- 48.0 months $^{2}$} \\
\hline & Male & 43 & $-1.39(0.8)$ & $-0.24(0.7)$ & $-1.56(0.7)$ & - & $16 \%(7)$ & $21 \%(9)$ \\
\hline & Female & 55 & $-1.70(0.8)$ & $-0.43(0.8)$ & $-1.66(0.7)$ & $4 \%(2)$ & $20 \%(11)$ & $15 \%(8)$ \\
\hline \multicolumn{9}{|c|}{ 48.1- 60.0 months } \\
\hline & Male & 60 & $-1.42(1.0)$ & $-0.65(1.0)$ & $-1.37(1.0)$ & $5 \%(3)$ & $22 \%(13)$ & $13 \%(8)$ \\
\hline & Female & 53 & $-1.33(0.9)$ & $-0.55(1.0)$ & $-1.25(0.8)$ & $2 \%(1)$ & $19 \%(10)$ & $11 \%(6)$ \\
\hline \multicolumn{9}{|c|}{ Overall } \\
\hline & Male & 122 & $-1.39(1.0)$ & $-0.37(1.0)$ & $-1.46(0.9)$ & $2 \%(3)$ & $21 \%(26)$ & $19 \%(23)$ \\
\hline & Female & 126 & $-1.53(0.9)$ & $-0.46(0.9)$ & $-1.48(0.8)$ & $2 \%(3)$ & $21 \%(27)$ & $14 \%(17)$ \\
\hline
\end{tabular}

${ }^{1}$ Results presented in mean (SD); abbreviations used WAZ - weight-for-age z score, HAZ - height-for-age z score, WHZ - weight-for-height $\mathrm{z}$ score; stunted defined as $\mathrm{HAZ}<-2.0$; underweight defined as $\mathrm{WAZ}<-2.0$; and thinness defined as WHZ $<-2.0$.

${ }^{2}$ Males had significantly higher HAZ $(\mathrm{p}=0.04)$ in this age category.

Table 3. Average daily nutrient intake among $<36.0$ months old children ${ }^{1}$

\begin{tabular}{|c|c|c|c|c|c|c|c|}
\hline & \multirow[b]{2}{*}{$R D A$} & \multicolumn{3}{|c|}{ Male } & \multicolumn{3}{|c|}{ Female } \\
\hline & & Mean & $S D$ & Median & Mean & $S D$ & Median \\
\hline Energy (MJ/d) & 5.69 & 6.2 & 1.0 & 5.9 & 5.0 & 0.4 & 5.1 \\
\hline Protein (g/d) & 16 & 51.1 & 1.5 & 55.1 & 30.8 & 1.2 & 31.3 \\
\hline Fat $(g / d)$ & - & 29.7 & 7.6 & 25.5 & 21.4 & 4.53 & 18.4 \\
\hline Calcium (mg/d) & upto 500 & 362.1 & 69.1 & 334.0 & 840.0 & 428.2 & 1081.7 \\
\hline Phosphate (mg/d) & - & 577.8 & 67.9 & 533.1 & 524.6 & 71.5 & 521.7 \\
\hline Folate (mg/d) & 100 & 44.0 & 7.4 & 45.4 & 18.7 & 5.4 & 19.9 \\
\hline$\beta$ carotene $(\mathrm{mg} / \mathrm{d})$ & 250 & 230.0 & 1.9 & 315.8 & 318.7 & 1.3 & 364.3 \\
\hline Iron (mg/d) & 4.8 & 16.7 & 3.8 & 11.5 & 14.9 & 1.4 & 12.2 \\
\hline Zinc (mg/d) & - & 2.7 & 0.9 & 3.5 & 5.3 & 3.3 & 3.2 \\
\hline $\operatorname{Vitamin} \mathrm{D}(\mathrm{mg} / \mathrm{d})$ & 10 & 27.9 & 14.7 & 19.2 & 32.1 & 9.4 & 24.0 \\
\hline
\end{tabular}

\footnotetext{
${ }^{1}$ Abbreviations used RDA - recommended daily allowance; SD - standard deviation.

${ }^{2}$ Mean intake indicated in bold letters are significantly higher $(\mathrm{p}<0.05)$ than their counterparts $(\mathrm{t}$-test $)$; percentage of subjects with less than RDA for energy intake male $33 \%(n=6)$, female $100 \%(n=15)$.
} 
Table 4. Average daily nutrient intake among 36.1 - 48.0 months old children ${ }^{1}$

\begin{tabular}{|c|c|c|c|c|c|c|c|}
\hline & \multirow[b]{2}{*}{$R D A$} & \multicolumn{3}{|c|}{ Male } & \multicolumn{3}{|c|}{ Female } \\
\hline & & Mean & $S D$ & Median & Mean & $S D$ & Median \\
\hline Energy $(\mathrm{MJ} / \mathrm{d})$ & 5.77 & 6.0 & 1.6 & 5.5 & 5.8 & 1.3 & 6.0 \\
\hline Protein (g/d) & 20 & 34.5 & 1.6 & 36.1 & 37.1 & 1.8 & 40.0 \\
\hline Fat $(\mathrm{g} / \mathrm{d})$ & - & 27.5 & 10.2 & 27.4 & 23.3 & 10.8 & 20.9 \\
\hline Calcium (mg/d) & upto 500 & 508.1 & 244.7 & 468.6 & 571.5 & 219.3 & 600.2 \\
\hline Phosphate (mg/d) & - & 528.7 & 204.8 & 507.3 & 579.7 & 248.9 & 539.2 \\
\hline Folate (mg/d) & 100 & 44.4 & 28.6 & 45.2 & 45.6 & 25.5 & 40.4 \\
\hline$\beta$ carotene $(\mathrm{mg} / \mathrm{d})$ & 300 & 212.3 & 1.53 & 264.7 & 166.4 & 3.2 & 241.7 \\
\hline $\operatorname{Iron}(\mathrm{mg} / \mathrm{d})$ & 5.9 & 8.8 & 3.1 & 7.2 & 7.3 & 1.7 & 6.9 \\
\hline $\operatorname{Zinc}(\mathrm{mg} / \mathrm{d})$ & - & 3.8 & 1.9 & 3.0 & 3.2 & 1.9 & 3.2 \\
\hline Vitamin D (mg/d) & 10 & 20.4 & 5.64 & 4.5 & 26.9 & 7.9 & 12.0 \\
\hline
\end{tabular}

${ }^{1}$ Abbreviations used RDA - recommended daily allowance; SD - standard deviation; percentage of subjects with below RDA energy intake male $58 \%(21)$, female $47 \%(n=21)$.

Table 5. Average daily nutrient intake among $\mathbf{4 8 . 1}-\mathbf{6 0 . 0}$ months old children ${ }^{1}$

\begin{tabular}{|c|c|c|c|c|c|c|c|}
\hline & \multirow[b]{2}{*}{$R D A$} & \multicolumn{3}{|c|}{ Male } & \multicolumn{3}{|c|}{ Female } \\
\hline & & Mean & $S D$ & Median & Mean & $S D$ & Median \\
\hline Energy $(\mathrm{MJ} / \mathrm{d})$ & 5.77 & 6.3 & 1.1 & 6.3 & 5.7 & 1.3 & 5.6 \\
\hline Protein (g/d) & 20 & 48.0 & 1.7 & 48.5 & 36.4 & 1.7 & 33.1 \\
\hline Fat $(g / d)$ & - & 24.7 & 6.2 & 24.3 & 23.9 & 11.3 & 23.3 \\
\hline Calcium (mg/d) & upto 500 & 570.6 & 283.5 & 549.2 & 367.3 & 256.4 & 285.2 \\
\hline Phosphate (mg/d) & - & 591.9 & 235.8 & 589.6 & 512.3 & 212.9 & 456.6 \\
\hline Folate (mg/d) & 100 & 53.5 & 32.7 & 43.4 & 45.9 & 25.4 & 47.0 \\
\hline$\beta$ carotene $(\mathrm{mg} / \mathrm{d})$ & 300 & 208.1 & 2.3 & 250.3 & 194.2 & 2.5 & 247.9 \\
\hline $\operatorname{Iron}(\mathrm{mg} / \mathrm{d})$ & 5.9 & 10.5 & 2.5 & 10.7 & 14.8 & 5.2 & 8.2 \\
\hline Zinc (mg/d) & - & 4.4 & 3.1 & 3.2 & 3.0 & 2.7 & 3.4 \\
\hline $\operatorname{Vitamin} \mathrm{D}(\mathrm{mg} / \mathrm{d})$ & 10 & 38.8 & 10.1 & 33.4 & 18.3 & 5.6 & 14.5 \\
\hline
\end{tabular}

${ }^{1}$ Abbreviations used RDA - recommended daily allowance; SD - standard deviation.

${ }^{2}$ Mean intake indicated in bold letters are significantly higher $(\mathrm{p}<0.05)$ than their counterparts $(\mathrm{t}$-test); percentage of participants with below RDA energy intake male $33 \%(n=16)$, female $56 \%(n=25)$. 
There was no significant correlation between the nutrient intake and anthropometric parameters. The total dietary energy intake was significantly correlated with intakes of protein $(r=0.60, p<0.001)$, fat $(r=0.69, p<0.001)$, calcium $(\mathrm{r}=0.40, \mathrm{p}<0.001)$, phosphate $(\mathrm{r}=0.48, \mathrm{p}<0.001)$, folate $(0.48, \mathrm{p}<0.001), \beta$-carotene $(\mathrm{r}=0.37, \mathrm{p}<0.001)$ and vitamin $\mathrm{D}(\mathrm{r}=0.22, \mathrm{p}<0.05)$. The dietary fat intake was significantly correlated with dietary intakes of $\beta$-carotene $(\mathrm{r}=0.50, \mathrm{p}<0.001)$, vitamin $\mathrm{D}(0.54, \mathrm{p}<0.001)$, protein $(\mathrm{r}=0.20$, $\mathrm{p}=0.04)$, calcium $(\mathrm{r}=0.32, \mathrm{p}=0.001)$ and phosphate $(\mathrm{r}=0.24$, $\mathrm{p}=0.01)$. Dietary intake of vitamin $\mathrm{D}$ was positively correlated with calcium intake $(r=0.37, p<0.001)$.

\section{Discussion}

This report is part of a comprehensive study on nutrition intervention among preschool children in southern Sri Lanka. We have observed a lower percentage $(<3 \%)$ of stunting in the sample. Further $(21 \%)$ of the children were underweight. These figures appear little below the national figures of $6 \%$ of stunting and $30 \%$ of underweight reported in year 2000 for this age group [5].

The energy intake of male children studied was adequate compared to their recommended allowances. It was found that females took significantly $(\mathrm{p}<0.05)$ less amount of calories per day than males. These results are similar to the reported data from India [1, 6], Ghana [7] and Maldives [8]. The lower intake of energy by children was mainly due to inadequate intake of energy rich food.

The daily mean intake of protein in males was $42.1 \mathrm{~g} /$ day (recommendation is $20 \mathrm{~g} /$ day). Hence, the protein intake is $210 \%$ of RDA. Female children had a daily protein intake of $36.30 \mathrm{~g} /$ day which was $181 \%$ of RDA. These findings are consistent with those reported from India and Africa [1,7,9].

Fat is a concentrated source of energy and imparts palatability to the diet. The minimum dietary fat intake is set as $15 \%$ of energy by WHO [10]. There was no significant $(p<0.05)$ difference in the fat intake of males and females. Both sexes derived almost $15 \%$ of their daily energy intake by fat.

Overall $\beta$-carotene intake was inadequate (three fourth of RDA) in the diet of preschool children. This may be due to the low intake of green leafy vegetables and fruits. These findings are similar to other studies which showed that preschool children consume $\beta$-carotene less than the recommended levels $[1,8]$. We found that vitamin D intake was 2.5-3 times the recommended intake. We were unable to find any previous study on the dietary vitamin D intake.

In the present study, preschool children consumed less folic acid rich food and their mean daily intake of folic acid was less than half the RDA. A significant $(\mathrm{p}<0.05)$ difference was observed in folic acid intake of 3 year old males and females (males consumed higher amount of folic acid than females). The intake of folic acid is variable among preschool children according to the studies $[1,11]$.

The overall mean calcium intake was around the recommendation in both males and females of the study sample. In contrast other studies have shown that intake of calcium was less than the RDA among preschool children in other countries $[7,12]$.

Iron intake of females was higher (double the RDA) than in males. However, studies from India show an inadequate intake of dietary iron among preschool children $[1,11]$. There were no regional reports on dietary zinc intake. The recommended zinc intake (RNI) of WHO/FAO is 5-6 mg [13]. Sri Lankan children had only half of this recommendation and it could be due to their poor animal protein consumption.

The limitation of our study would be the possibility of under-reporting since parents were the only informants. Since they prepare the food, even if they remember the key ingredients, amounts consumed by the kids may not have been stated clearly. In the present survey we did not reject under-reported participants for several reasons. As it has been reported elsewhere if over-reporting is also assumed to be present in the results, the exclusion of presumed under-reporters can cause the results to be unreliable [14]. Another reason is that the calculation of a cut-off value for rejection requires specific information about the physical activity level of the children, which is not available in this study.

In summary, the intake of fat, folic acid and zinc by children aged 3-5 years was inadequate. The intake of energy, protein, calcium, $\beta$-carotene, vitamin $\mathrm{D}$ and iron was satisfactory. The consumption of nutrients and energy in particular was better in males than in females. However, females had a better dietary iron intake than males. The dietary macro- and micro-nutrient intake by both males and females increase exponentially with age. It appears that there is need to develop sound food habits among preschool children that may help their overall growth and development.

\section{Acknowledgements}

This project was assisted by a grant from the International Atomic Energy Agency (IAEA-SRL-11958). We acknowledge Ms. A. A. Anushka and Ms. Malithi Kariyawasam for their assistance in collecting and computing dietary intake data. The parents of the study subjects are acknowledged for their cooperation and assistance at data collection. 


\section{References}

1. Manu, Khetarpaul N. Nutritional profile of Indian rural preschoolers. Nutrition and Food Science 2005; 35: 428-35.

2. UNICEF. A UNICEF policy review: Strategy for improved nutrition of children and women in developing countries. 1990, United Nations Children's Fund, New York, USA.

3. ASEAN food composition tables. ASEAN Network of food Data System. ASEAN FOODS Regional Centre. 2000, Mahidol University, Thailand.

4. Nutrition Guide - 2000 Ministry of Health and Indegenous Medicine, Sri Lanka. 2000.

5. Annual Health Bulletin-2002 Ministry of Health, Sri Lanka. 2002.

6. Rana K, Hussain M. Body weight status of preschool children belonging to HIG in relation to nutrient intake. Indian Journal of Nutrition Research 2001; 38: 236-41.

7. Takyi EE. Nutritional status and nutrient intake of preschool children in northern Ghana. East African Medical Journal 1999; 76: 510-5.

8. Golder AM, Erhardt JG, Scherbaum V, Saeed M, Biesalski HK, FuErst P. Dietary intake and nutritional status of women and pre school children in the Republic of the Maldives. Public Health Nutrition 2001; 4: 773-80.
9. Hoorweg G, Foeken T, Klaver W, Okeloo W, Veermen W. Nutrition in agriculture development, settlement in post province, Kenya. Ecology of Food and Nutrition 1996; 35 : $161-81$.

10. $\mathrm{WHO} / \mathrm{FAO}(\mathrm{WHO} / \mathrm{FAO})$. Diet, nutrition and the prevention of chronic diseases. Report of a joint WHO/FAO expert consultation. 2003, WHO Technical Report Series 916.

11. Singh I, Khosla S. Impact of nutrition education on the mothers of anaemic preschool children. Journal of Research Punjab Agricultural University. 2000; 37: 246-52.

12. Leung SS, Chan SM, Lui S, Lee WT, Davies DP. Growth and nutrition of Hong Kong children aged 0-7 years. Journal of Pediatric and Child Health 2000; 36: 56-65.

13. World Health Organization and Food and Agriculture Organization of the United Nations. Vitamin and Mineral Requirements in Human Nutrition. Joint FAO/WHO consultation on human vitamin and mineral requirements. Geneva: FAO/WHO, 2004.

14. Black AE, Goldberg GR, Jebb SA, Livingstone MB, Cole TJ, Prentice AM. Critical evaluation of energy intake data using fundamental principles of energy physiology: 2 . Evaluating the results of published surveys. European Journal of Clinical Nutrition 1991; 45: 583-59. 